\title{
Vitamin D status and body composition in UK Caucasian and South Asian postmenopausal women: results from the DFINES II study
}

\author{
M. M. Mendes ${ }^{1,2}$, A. L. Darling ${ }^{2}$, L. Meira ${ }^{3}$ and S. A. Lanham-New ${ }^{2}$ \\ ${ }^{1}$ Faculty of Nutrition, Federal University of Goiás, Goiânia, Goiás, Brazil, ${ }^{2}$ Department of Nutritional Sciences and \\ ${ }^{3}$ Department of Biochemistry and Physiology, School of Biosciences and Medicine, Faculty of Health and Medical \\ Sciences, University of Surrey, Guildford, Surrey, UK, GU2 $7 X H$
}

Several recent studies have suggested an influence of body composition on vitamin D status in humans. Lower concentrations of 25-hydroxvitamin D (25OHD) have been associated with increased risk of osteoporosis, insulin resistance, heart disease and cancer. ${ }^{(1)}$ This study aimed to assess the difference in 25OHD status between Caucasian and South Asian women and to determine whether there was an association between body composition and $25(\mathrm{OH}) \mathrm{D}$ status in these two population groups as part of our on-going Vitamin D research at Surrey.

In 2010 the D-FINES II study (Vitamin D, Food Intake, Nutrition and Exposure to Sunlight in Southern England) further investigated 82 Surrey Caucasian and South Asian postmenopausal women for vitamin D status (25-hydroxyvitamin D-25OHD) and anthropometric measures such as Body Mass Index (BMI), weight, waist and hip. This was a follow on to the main D-FINES study in 2006-2007. (2)

As shown in Table 1 below, significant differences were found in 25OHD status between the Caucasians and South Asian women (median 82 [21.3] nmol/l, $n=56$ vs. 52.5 [21.4] nmol/l, $n=19$ ) respectively $P<0.001$ ).

Table 1. Vitamin D status and anthropometric measures

\begin{tabular}{|c|c|c|c|c|c|c|c|c|c|c|c|c|}
\hline & \multicolumn{6}{|l|}{ Caucasians } & \multicolumn{6}{|l|}{ Asians } \\
\hline & $25 \mathrm{OHD} \mathrm{nmol} / \mathrm{L}$ & BMI & Weight kg & Height $\mathrm{m}$ & Waist $\mathrm{cm}$ & Hip cm & $25 \mathrm{OHD} \mathrm{nmol} / \mathrm{L}$ & BMI & Weight kg & Height $\mathrm{m}$ & Waist $\mathrm{cm}$ & $\overline{\text { Hip } \mathrm{cm}}$ \\
\hline $\mathrm{N}$ & 56 & 61 & 61 & 61 & 61 & 61 & 19 & 21 & 21 & 21 & 21 & 21 \\
\hline Mean & 83.9 & 25.6 & 67.2 & 162.1 & 90.1 & 104.9 & 57.3 & 29.2 & 70.0 & 154.6 & 94.0 & 109.2 \\
\hline Median & 82.0 & 24.5 & 64.0 & 161.0 & 90.0 & 104.0 & 52.5 & 28.1 & 65.0 & 155.5 & 98.0 & 108.0 \\
\hline Std.Dev & 21.3 & 4.8 & 12.0 & 6.3 & 10.8 & 10.2 & 21.4 & 4.5 & 11.1 & 4.1 & 9.6 & 10.44 \\
\hline Min. & 39.3 & 19.0 & 44.0 & 148.5 & 70.0 & 87.0 & 25.0 & 22.1 & 54.0 & 144.0 & 78.0 & 93.0 \\
\hline Max. & 141.5 & 38.7 & 103.0 & 180.0 & 116.0 & 132.0 & 95.3 & 40.1 & 91.0 & 161.5 & 107.0 & 126.0 \\
\hline
\end{tabular}

Spearman's correlations were applied to vitamin D and anthropometric analyses, and in Caucasians there was a significant negative association between 25OHD status and BMI $(r=-0.352, P<0.008), 25 \mathrm{OHD}$ status and weight $(r=-0.314, P<0.006)$. Similar findings were also seen for waist and hip circumference measurements $(r=-0.398, P<0.002 ; r=-0.420, P<0.001$ respectively. For South Asians, there was no significant correlation between vitamin D status and any of the anthropometric measures.

Overall, the study suggests that anthropometric measures, specifically BMI, weight, waist and hip, are inversely associated with 25-hydroxyvitamin D (25OHD) in Caucasians. The most likely explanation for this would be the lower bioavailability of vitamin D circulating because of its deposition in adipose tissue. This association could also be affected by clothing habits and limited mobility in overweight or obese people ${ }^{(3)}$. Further research is required to examine the $25 \mathrm{OHD} /$ bone composition findings in ethnic groups.

MMM is a recipient of the Science Without Borders Programme.

The D-FINES original study was funded by the FSA (Project No. NO5064).

1. Snijder MB, van Dam RM, Visser M et al. (2005) J Clin Endocrinol Metab 90, 4119-4123.

2. Darling AL, Hart KH, Macdonald HM et al. (2013) Osteoporos Int 24, 477-488.

3. Pasco JA, Henry MJ, Nicholson GC et al. (2013) J Clin Endocrinol Metab 98, 886-890. 